\title{
CULTURA POLÍTICA DE ESTUDIANTES DE LICENCIATURA EN LA UNIVERSIDAD LA SALLE PACHUCA
}

Humberto Mejía Zarazúa*

\section{Resumen}

Se presentan algunos aspectos acerca del concepto de cultura política, así como algunos referentes lasallistas sobre educación política, a fin de presentar una referencia teórica a una investigación descriptiva y transeccional, mediante la aplicación de una encuesta a estudiantes de licenciatura de la Universidad La Salle Pachuca cuyo objetivo es describir algunos rasgos de su cultura política, se concluye que la dimensión política de la educación superior debe tener mayor importancia para la formación de ciudadanos críticos, reflexivos y que puedan fungir como agentes de cambio social.

\section{Abstract}

Some aspects about the concept of political culture are presented, as well as some Lasallian referents on political education, to present a theoretical reference to a descriptive and trans sectional research by implementing a survey to bachelor degree students of Universidad La Salle Pachuca with the aim of describing some features of their political culture, it is concluded that the political dimension of higher education should have greater importance for the formation of critical, reflexive citizens who can serve as social change agents.

Palabras clave: Cultura política, estudiantes universitarios, universidades lasallistas, dimensión política de la educación, democracia, ciudadanía.

Key words: Political culture, college students, Lasallian universities, political dimension of education, democracy, citizenship.

Ingeniero Agrícola y Maestro en Ciencias de la Educación. Colaborador de la Dirección de Posgrado e Investigación de la Universidad La Salle Pachuca.hmejia@lasallep.edu.mx 


\section{Introducción}

El presente reporte de investigación describe algunos rasgos de la cultura política de los estudiantes de licenciatura de la Universidad la Salle Pachuca y pretende responder a la pregunta general de investigación ¿Cuáles son las características de la cultura política de los estudiantes de licenciatura de la Universidad La Salle Pachuca? La idea de estudiar la cultura política de los universitarios lasallistas surge de la Dirección de Posgrado e Investigación en su afán de conocer uno de los aspectos más importantes del perfil de los jóvenes estudiantes relacionado con la intención institucional de formar profesionales que incidan en la transformación de la sociedad mexicana. Se parte del principio de que las universidades lasallistas además de formar profesionales altamente competentes en su respectivo ámbito, deben formar ciudadanos sensibles a la problemática social y capaces de incidir en la transformación social para reducir las desigualdades económicas, sociales y culturales de la población mexicana, es decir, en beneficio de los sectores más empobrecidos. Se considera que esta temática tiene su justificación en importantes referencias lasallistas que abordan la dimensión política de la educación superior y que la adquisición de la cultura política es un proceso multicausal, siendo la institución escolar uno de los espacios que coadyuvan en su construcción, por lo que es importante potenciar las posibilidades de la educación formal en el desarrollo de la mencionada cultura.

\section{Marco de Referencia}

\section{Proyecto PERLA}

El Proyecto Educativo Regional Lasallista Latinoamericano (PERLA) es el principal referente para enmarcar los esfuerzos académicos de la Universidad La Salle Pachuca ya que parte de un diagnóstico de la problemática social de América Latina y el Caribe (ALC) que se caracteriza por los altos niveles de pobreza, desigualdad y exclusión. Como veremos, los estudiantes de licenciatura de la Universidad La Salle Pachuca no están ajenos a lo que en PERLA a través de Azmitia (2006: 14-15) refiere:

Los elevados índices de pobreza de la región y el incremento de la desigualdad hacen cada vez más precarios y vacíos de contenido a los sistemas políticos electorales... 
Esto conduce, desafortunadamente, a que cada día sea mayor el número de ciudadanos y ciudadanas que cuestionen el valor del modelo democrático y lo asocian con mayor pobreza, mayor corrupción, mayor demagogia e injusticia.

Los Estados latinoamericanos son estados en "crisis permanente" debido, entre otras razones a democracias de muy baja intensidad y calidad, la negación de la ciudadanía para los excluidos, la privatización del espacio público, el clientelismo, la corrupción, la inseguridad, la violencia y una débil soberanía. Azmitia (2006: 17-18) añade que:

Incluso la propia democracia electoral se ve cuestionada por la realidad actual. Un efecto de la misma ha sido la pérdida de confianza y credibilidad de la población en los partidos políticos y sus dirigentes. El abuso de la demagogia, el incumplimiento de promesas, la entronización de la corrupción y el narcotráfico en los Estados, el empeoramiento de la situación ha llevado a millones a cuestionarse el valor de la política y de los políticos.

Ante lo expuesto, surge la necesidad de formar ciudadanos activos que mediante acciones organizadas participen el la formulación de políticas y ejerzan un control tanto del Estado como del mercado, en este sentido en PERLA se aclara que "la educación sola no cambia la sociedad, pero si la educación no cambia, no cambiará la sociedad" (Azmitia, 2006: 31). Asimismo PERLA entiende la democracia "como promoción de una cultura de la paz y la justicia para la que hay que educarnos y educar en una nueva ciudadanía, para una economía solidaria y un desarrollo sustentable" (Azmitia, 2006: 58) y propone establecer programas de estudio para profundizar en la dimensión ética y política de la educación.

\section{Algunos referentes lasallistas sobre educación política}

Se considera importante mencionar otros referentes lasallistas sobre la dimensión política de la educación superior. Por ejemplo Enrique Aguayo $^{1}$ (2006) considera que la Universidad La Salle debe ser un espacio plural, tanto en lo cultural como en la condición socioeconómica y agrega que su misión es reducir la desigual distribución de la riqueza; sus egresados deben contribuir a disminuir la discriminación racial, la corrupción y la delincuencia. Choquet (2006) indica que el servicio a la sociedad y la educación de los jóvenes es el sentido de la 
misión lasallista bajo principios de compromiso, vocación de servicio y lucha contra la desigualdad y el individualismo. Asimismo menciona que usualmente los jóvenes al ingresar a la universidad sienten como propios estos principios, pero también es común

1 Catedrático de la Facultad de Filosofía de la Universidad La Salle Ciudad de México.

que al ingresar al mercado laboral el actuar de los profesionales tienda a ser acorde con la tendencia social dominante: individualismo, pérdida de compromiso y voluntad para mejorar las condiciones de vida de la colectividad.

Para Craig Franz ${ }^{2}$ (2006: 34) uno de los propósitos de la misión lasallista es ofrecer oportunidades educativas a los necesitados, así como atender, de manera sensible, las necesidades sociales del área local, de manera que la educación terciaria lasallista, en los años siguientes deberá trabajar, entre otros aspectos, los relativos a "madurar nuestra conciencia social" e "influenciar la dinámica de la globalización". En opinión de Edgar Hengemüle ${ }^{3}$ (2006) en la universidad lasaliana debe reinar un ambiente fraterno y de respeto a las diferencias, además no debe ser una entidad aislada sino abierta a la sociedad en la que se inserta para estar a su servicio a través de la educación, también acota que "contribuiremos a la promoción de la persona humana y a la superación de la pobreza de la injusticia social, estudiando con nuestros alumnos las raíces de la pobreza y de la injusticia, promoviendo en ellos la conciencia y el compromiso social" (Hengemüle, 2006: 56). Juan Antonio Ojeda ${ }^{4}$ (2006) opina que es importante recuperar el espíritu crítico e innovador de la universidad, aunque asume que en el contexto educativo domina la cultura del individualismo, por lo que hay que impulsar la colaboración interna entre los diferentes actores de una universidad lasallista (alumnos, profesores, administrativos, directivos) y reconocer que carecemos de la formación necesaria para trabajar en equipo. Se requiere también de colaboración externa, ya que toda universidad que quiera prestar un servicio a la sociedad debe establecer un conjunto de relaciones y colaboraciones fuera del entorno del campus y del quehacer diario (convenios con otras universidades, empresas, instituciones públicas y privadas, asociaciones e individuos). Considera que en una universidad lasallista se procura que los alumnos tengan conocimiento de la realidad social en la que están inmersos, y que: 
Presidente de Saint Mary's University de Minesota (EUA) y presidente emérito de Saint Mary's Çollege de California (EUA). Fundador de la Asociación Internacional de Universidades Lasallistas.

3 Fue Coordinador del Departamento de Pedagogía y Pastoral Universitario para el Distrito de Posrto Alegre, Brasil y Presidente y Secretario Ejecutivo para la Región Lasallista de Latinoamérica.

4 Decano del Centro La Salle de estudios Universitarios y Presidente de la asociación de Centros de enseñanza Universitaria para la Iglesia a nivel nacional.

Deberíamos compartir programas y buenas prácticas, potenciar las acciones de voluntariado y la formación que requieren y tratar de superar ese nivel asistencial y de voluntariado por un compromiso y unas acciones más estables y profesionalizadas (Ojeda, 2006: 82).

José Cervantes ${ }^{5}$ (2006) aduce que la universidad como institución surgió hace casi mil años, sigue formando dirigentes y también sigue siendo un espacio para la crítica social. Ha sobrevivido al renacimiento, la ilustración y al modernismo. Ahora, la globalización coloca al conocimiento como un factor protagonista y fundamental para el desarrollo, aunque con un enfoque de productividad, eficiencia y competitividad que no toma en cuenta la naturaleza del humano, de manera que "el modelo de ser humano en muchas ofertas educativas está mutilado" (Cervantes, 2006: 17). El autor menciona la tendencia del alumnado a ser presa de intereses de goce efímero, entre otras razones por vivir en una sociedad compleja y fragmentada, ante esto añade la importancia del lasallismo, en tanto una universidad católica es espacio de encuentro, diálogo y convivencia de todas las clases sociales: "Creo que traicionaría a la esencia misma de la universidad, el volverse clasista o elitista. Aunque la universidad contara con muchos programas de desarrollo social, estos se tornarían en programas sociales asistenciales" (Cervantes,2006: 25). Ante la encrucijada económica, política, ideológica y ética, se han

perdido consensos sobre diversos aspectos como el género, la identidad sexual, el multiculturalismo, la política y los derechos de las minorías. Al ser la universidad católica formadora de valores, debe manifestar su posición ante estos aspectos, desde un punto de vista esperanzador y transformador de la sociedad, en este sentido Cervantes (2006: 27) acota que: 
La universidad católica, por su nombre, no es neutra ni apolítica. Tampoco, a riesgo de sacrificar su naturaleza misma, es partidista. La universidad católica en el desempeño de su rol profético puede tomar muchas formas, pero favorece la compasión y la responsabilidad social teniendo como meta el conquistar las posibilidades de una

Ha sido Presidente de la federación de Instituciones Particulares de Educación Superior (FIMPES), fundador de la Universidad de Monterrey, ULSA Noroeste (Cd. Obregón) y ULSA Chihuahua, así como Rector de la Universidad La Salle de la Ciudad de México, Cd. Obregón y Chihuahua.

mayor felicidad humana, de un ciudadano más crítico, para que la justicia prive en todas las relaciones y para que la democracia económica y política sea una realidad.

Louis De Thomasis ${ }^{6}$ (2006) opina que la justicia, la conciencia y la responsabilidad social son conceptos guías del quehacer educativo lasallista y cuyos propósitos deben ser orientados a mejorar las condiciones de vida de los pobres, los marginados y los oprimidos y añade que:

Debemos comprender, por lo tanto, que el problema es sistémico. En consecuencia, cualquier solución viable contra la injusticia social y la pobreza también debe ser sistémica. Ahí yacen los nuevos retos y oportunidades de la educación superior lasallista. Nuestro carisma lasallista debe impulsarnos a crear una nueva infraestructura educativa que se extienda más allá de las necesidades educativas de los pobres...y fomente un cambio sistémico en toda la educación superior lasallista que se aboque al núcleo mismo de las estructuras, los sistemas y las dinámicas de la sociedad...La visión lasallista para la educación superior del tercer milenio nos debe impulsar a crear una infraestructura innovadora en la que nuestros cuerpos docentes, nuestra investigación y nuestra currícula nos den el poder para enseñar a los pobres directamente, y también ayudar a nuestros alumnos (aún los más privilegiados) a aprender y a poseer la "herramientas" para cambiar tanto al mundo como a las fuerzas sistémicas y estructurales que crean a los pobres de este mundo (De Thomasis, 2006: 62-63).

En opinión de Carlos Gómez Restrepo ${ }^{7}$ (2006) en América Latina se deben reconocer lo problemas de pobreza violencia, exclusión, fragilidad de las democracias y la injusta distribución de la riqueza. Como consecuencia de lo anterior las instituciones lasallistas requieren ser "menos inocuas... 
Esto implica que no se puede seguir teniendo posiciones políticas tan desteñidas si de por medio está la suerte de los pobres en el mundo en que a poca gente le importa su suerte" (Gómez, 2006: 132). Este autor asume que la pobreza entendida como carencia de bienes es fruto de la injusticia y el despojo

6 Canciller de Saint Mary's University de Minnesota (EUA), fue fundador y presidente de Christian Brothers Investment Services, Inc.

Docente en varias escuelas preparatorias en Colombia y ha sido Secretario Ejecutivo de la Región Lasallista Latinoamericana y es Vicerrector de la Universidad La Salle en Bogotá, Colombia.

económico, político y social de los pueblos. Así, la universidad lasallista debe estudiar la realidad de los pobres y proponer alternativas de superación, por otro lado explica que el servicio a los pobres se da en tres niveles: el de asistencia y beneficencia; el de promoción y desarrollo humano; y el nivel estructural-transformador:

El nivel de asistencia y beneficencia, en donde las universidades lasallistas ejercen la caridad y el amor operativo con actividades de beneficencia inmediatas, de asistencia a las necesidades y carencias de las poblaciones, las cuales no dan espera (ej: hambre, enfermedades, desastres naturales)...El nivel de promoción y desarrollo humano, por el cual las universidades lasallistas...haciendo que los pobres se vuelvan protagonistas de su propio desarrollo. Para ello las universidades pueden proporcionar condiciones de bienestar y calidad de vida interviniendo interdisciplinariamente comunidades de las ciudades o sectores rurales deprimidos, mediante la organización comunitaria, la creación de microempresas, el urbanismo, la educación, la salud, etc.

$Y$ el nivel estructural transformador, que es lo propio de las universidades, por lo cual dan respuestas estructurales a los grandes problemas sociales. Es el amor político y la caridad social hechos vida mediante la organización comunitaria y la autodeterminación. Aquí entran las inmensas posibilidades para el actuar lasallista comprometido en los campos de la ética, la mística y la política. En consecuencia el signo distintivo de una universidad lasallista es su trabajo por la promoción de la justicia y los derechos humanos. Personas, ciencia y técnica al servicio de los más pobres de nuestros pueblos (Gómez, 2006: 139, 140). 
Por lo anterior, Gómez Restrepo (2006) afirma que la educación no puede disociarse de sus implicaciones políticas, por lo que las universidades lasallistas deben asumir el compromiso de transformar las estructuras actuales de dominación y contribuir con una función de interlocución entre el Estado y la sociedad civil, principalmente con relación a las problemáticas de la niñez y la juventud. Lo anterior supone asumir una forma crítica el papel de la universidad y propiciar una presencia ética y política en sus áreas de influencia.

\section{Cultura política}

La construcción de la identidad es fundamental en la conformación de la cultura política, por lo tanto en ésta también intervienen imbricaciones axiológicas y praxiológicas del individuo y la colectividad de pertenencia. La construcción identitaria que deriva, entre otras cosas, en la construcción cultural de la política, es un asunto complejo, ya que la familia y los grupos inmediatos de pertenencia del sujeto, como la escuela, no son suficientes para explicar la complementariedad y/o fragmentación de la identidad, pues existe toda una red de relaciones y medios de socialización que desbordan los ámbitos tradicionales en los que se desenvuelve el individuo contemporáneo (Molina, 2004). Para Adrián Acosta (2005: 38) la cultura política es "una conjunción de costumbres y tradiciones que configuran la subjetividad política". Para Durand Ponte (1998) es el conjunto de reglas que posibilitan a los actores calcular sus acciones políticas, y agrega: "En la aplicación de esas reglas, en su uso, se incluyeno movilizanvalorespolíticos, conceptualizaciones, informaciones, resultados de experiencias participativas, evaluaciones del sistema o partes del mismo, sentimientos y emociones, que posibilitan el cálculo de la acción" (Durand, 1998: 15).

El enfoque que Almond y Verba (1992) utilizaron para la conceptualización de la cultura política es el relativo a la culturapersonalidad $o$ enfoque psicocultural referidas a orientaciones, posturas y actitudes específicamente políticas, así la cultura política de una sociedad involucra conocimientos, sentimientos y valoraciones de determinada población. Para los fines de este estudio, se parte de que la cultura política implica una serie de prácticas cotidianas (no sólo en el ámbito propio de la política), que no únicamente se refieren al espacio público, sino también a los espacios escolares y familiares, y que repercuten en la calidad de la democracia y el bienestar de la población. 


\section{Cultura política en México}

Aún cuando el tema de la cultura política en México se ha tratado desde hace varias décadas, es a finales de los ochenta que cobra mayor importancia. La cultura política se ha estudiado desde los valores nacionales y políticos, la participación ciudadana, la formación cívica y la educación acerca de los derechos humanos, entre otros (Molina, 2004). Por ejemplo, Belinde García (2002) identifica algunos factores que representan obstáculos para la participación política, entre ellos se encuentran el bajo nivel educativo, el desempleo y la crisis económica, la antidemocracia y la centralización del poder, la corrupción, la desinformación, el incumplimiento de los derechos políticos, la desigualdad de oportunidades y la discriminación de género, entre otros. Una de las explicaciones expresadas es "La existencia de un sistema de Gobierno y una cultura política que excluye a las mayorías del ejercicio del poder e imposibilita la acción del individuo en su calidad de ciudadano" (B. García, 2002: 213).

El Instituto de Investigaciones Sociales de la UNAM realizó un estudio por encargo del Instituto Federal Electoral (IFE) dirigido por Julia Flores y Yolanda Meyenberg (2000), cuyo propósito fue elaborar un diagnóstico de carácter nacional del estado que guarda la cultura política en México. Resultó que sobre la política prevalece el desconocimiento, la desconfianza y desacuerdo sobre sus métodos, instrumentos e instituciones. Por lo que existe escaso o nulo interés en la política. Se reporta precario el asentamiento de valores como la tolerancia y una elevada predisposición a aceptar distintos principios de legitimidad del poder político, así como persistencia de percepciones de desapego y desconfianza en la ley.

Respecto a la segunda Encuesta Nacional sobre cultura Política y Prácticas Ciudadanas (ENCUP 2001) Algunos resultados relevantes son que 44 por ciento de los encuestados dice no hablar de política, 56 por ciento considera que la política es demasiado complicada y 78 por ciento dijo no haber leído las noticias políticas durante la semana pasada inmediata anterior a la aplicación de la encuesta. El principal medio de información sobre política fue la televisión $(79.8$ por ciento). En cuanto a percepciones sobre democracia, con base en tres opciones, 56 por ciento optó por la democracia aunque no asegure el avance económico y a 10 por ciento no le importa si hay democracia o dictadura (SEGOB; IFE, 2001). 
Para 2004 se detectó que "no hay malestar con la democracia, pero hay malestar en la democracia" (PNUD, 2004: 19). Para 2005 al parecer existió una búsqueda de consolidación democrática a través de expectativas reales de competencia electoral ante la elección presidencial y ante la desilusión de resultados de la transición de partido político en el poder puesto que se tenían bajos niveles de confianza en el gobierno y en el presidente, casi no se pensaba que las elecciones eran limpias, que existía una gran corrupción y que la democracia era muy deficiente (Latinobarómetro, 2005).

Según la Tercera Encuesta Nacional de Cultura Política y Prácticas Ciudadanas (ENCUP 2005) dos tercios de los encuestados (65 por ciento) contestaron que la política era complicada o muy complicada y solo uno de cada cinco opinó que era poco o nada complicada. 62 por ciento de los encuestados dijo que la televisión es el medio que más utiliza para informarse de lo que pasa en la política, 17 por ciento la radio y sólo una de cada 10 personas lo hace a través de los periódicos. 31 por ciento de los entrevistados considera que México sí vive en una democracia, 11 por ciento opina que sólo en parte, contra 23 por ciento que opina lo contrario y 28 por ciento declaró no saber si vivimos o no en una democracia. 47 por ciento dijo estar poco o nada satisfechos con la democracia en México, 20 por ciento manifestó estar ni satisfecho ni insatisfecho y 26 por ciento dijeron estar satisfechos y muy satisfechos. Cinco de cada 10 (52 por ciento) piensa que a los gobernantes les importan poco los ciudadanos, tres de cada 10 dijo que nada y sólo 10 por ciento consideró que mucho. Cuatro de cada 10 entrevistados (42 por ciento) consideró que los partidos políticos son poco necesarios, uno de cada 10 nada necesarios y 38 por ciento consideraron que son muy necesarios. 16 por ciento de los ciudadanos considera que en México las leyes se utilizan para defender los intereses de la sociedad y casi 2 de cada 10 (19 por ciento) que se utilizan para buscar la justicia, contra 33 por ciento que estima se utilizan para defender los intereses de la gente con poder y 26 por ciento considera se utilizan para cometer arbitrariedades. Se detectó un severo déficit de capital social entre los mexicanos, pues sólo uno de cada 10 entrevistados (14 por ciento) dijo pertenecer a una organización de vecinos, colonos y/o condominios. 10 por ciento en agrupaciones de ayuda social y 13 por ciento en organizaciones ciudadanas (SEGOB, 2005). 


\section{Método}

Es un estudio con enfoque cuantitativo, no experimental, descriptivo y transversal. Para el trabajo de campo se realizó una encuesta a los alumnos de licenciatura de todos los programas que imparte La Salle. EI cuestionario prioriza la dimensión afectiva y evaluativa y se excluye la dimensión cognitiva pues no se consideró conveniente aplicar un instrumento que pudiera percibirse como un examen por parte del estudiantado. Para el diseño del instrumento se consultó el aplicado por Mejía (2005) a estudiantes de la Universidad Autónoma del Estado de Hidalgo (UAEH), y el aplicado en la segunda y tercera Encuesta sobre Cultura Política y Prácticas Ciudadanas (2003 y 2005), a cargo de la Secretaría de Gobernación, asimismo se piloteo con aproximadamente cien estudiantes de Psicología de la UAEH de primero, segundo y séptimo semestre, a fin de asegurar la claridad del instrumento y también se sometió a análisis de validez por expertos ${ }^{8}$. Consta de 86 ítems agrupados en seis secciones: caracterización del estudiante, elección de opciones, escala Lickert, jerarquía de opciones, ubicación de nivel de confianza de diversas instituciones, calificación de grado de desarrollo de procesos. Los ejes analíticos bajo los cuales se construyó el instrumento son la valoración sobre la democracia en México, el Estado de derecho, la clase política, la noción y autoconcepto de ciudadanía, la interculturalidad, la pobreza, valoración sobre La Salle Pachuca, confianza en instituciones y desarrollo de procesos sociales en México.

El instrumento se aplicó durante el primer periodo semestral de 2008, en dicho periodo la matrícula reportada por la Coordinación de Sistemas para el periodo escolar enero-junio 2008 fue de 547 alumnos, si bien la intención fue aplicar un censo, sólo se aplicaron 471 cuestionarios que corresponden al

86.1 por ciento de la matrícula, donde 277 son mujeres (58.8 por ciento) y

194 hombres (41.2\%). El promedio de edad era de veinte años. 


\section{Resultados}

A continuación se da cuenta de los principales resultados generales de la encuesta realizada, éstos se presentan por eje analítico.

\section{Valoración sobre la democracia en México}

Respecto de la opinión acerca de la democracia en México, 44\% del alumnado opina que ésta se da en mayor medida que antes, $28 \%$ cree que sigue siendo como antes, y $24 \%$ opina que este régimen político nunca ha existido en México. Respecto al grado de satisfacción que se tiene con la democracia en México, podemos observar en la gráfica 1 que más de la mitad del alumnado encuestado está poco satisfecho con la democracia mexicana (54.1\%). Los demás resultados indican que $27.8 \%$ está medianamente satisfecho con la democracia en México, $17 \%$ nada satisfecho y $0.2 \%$ está totalmente satisfecho.

8 Jorge E. Peña Zepeda, Candidato a Doctor en Sociología y Gregorio Sánchez Muñoz, Mtro. en
Enseñanza Superior

Gráfica 1. Opinión sobre el grado de satisfacción de con la democracia en México

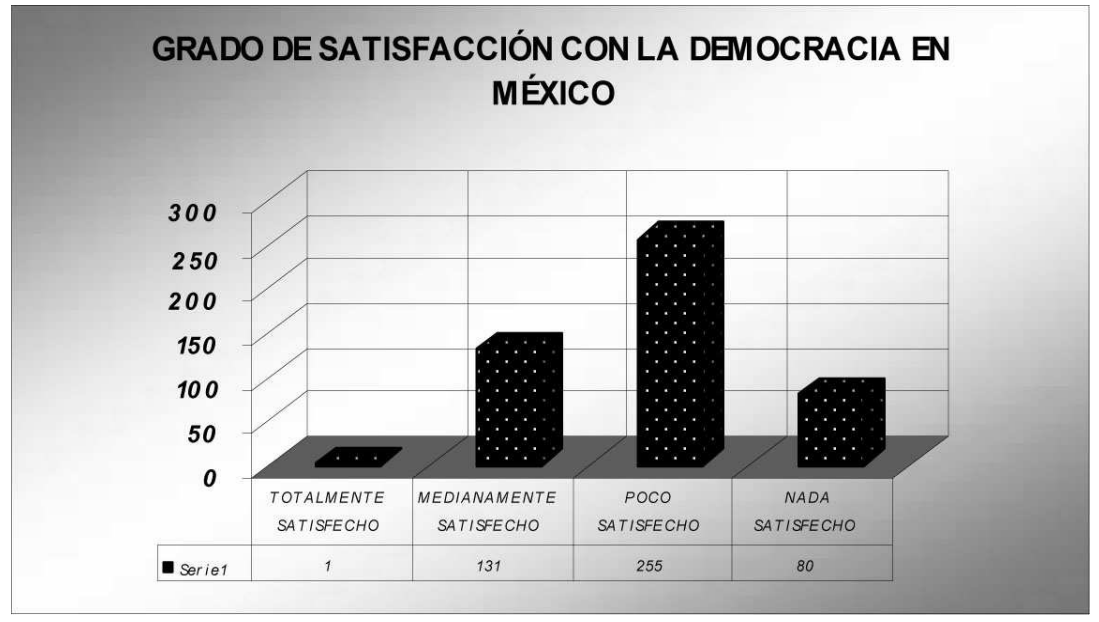

Fuente: Dirección de Posgrado e Investigación de La Salle Pachuca. 
En virtud de que diversas encuestas con muestras representativas de la población en general han reportado que existe una tendencia a sobrevalorar (en términos del supuesto avance democrático en México) determinado régimen autoritario siempre y cuando éste garantice un avance económico que se traduzca en la economía familiar de los mexicanos; se exploró una disyuntiva en el alumnado de La Salle Pachuca (sin opción a otra opinión) ${ }^{9}$, donde resulta que $76.2 \%$ del alumnado encuestado preferiría una democracia

que respete los derechos de todas las personas, aunque no asegure el avance económico y sólo $12.7 \%$ preferirían una dictadura que asegure el avance económico, aunque no respete los derechos de todas las personas.

También se exploró la opinión del estudiantado respecto al tipo de lucha que debe presentarse a favor de la democracia. El porcentaje mayoritario (48.8) se presenta en la opción que corresponde a la utilización de las vías legales aunque éstas no sean las idóneas para tal efecto. Respecto a que se debe recurrir tanto a vías legales como a estrategias de resistencia civil, se obtuvo

9 Precisamente porque en el pilotaje del cuestionario era evidente que la gran mayoría de
estudiantes existe claridad en que en el avance democrático, el respeto a los derechos
individuales deben ir a la par del avance económico

un porcentaje de 31 . Por último se estableció la opción más radical: optar tanto por la resistencia civil y/o la lucha armada por considerar inútiles las vías legales, ésta opinión alcanzó un porcentaje de 14.9.

Mediante la escala de actitudes la afirmación de que los ciudadanos mexicanos influyen mucho en las decisiones del gobierno obtuvo una opinión de parcial desacuerdo. Asimismo, se piensa que para que la democracia emerja y perdure en el país, es de mayor importancia una cultura democrática en las actitudes cotidianas de los ciudadanos, y en menor medida la obtención de un ingreso económico de éstos para una vida digna y el ejercicio al derecho al voto (grafica 2) 
Gráfica 2. Opinión sobre la condición que más importa para la democracia

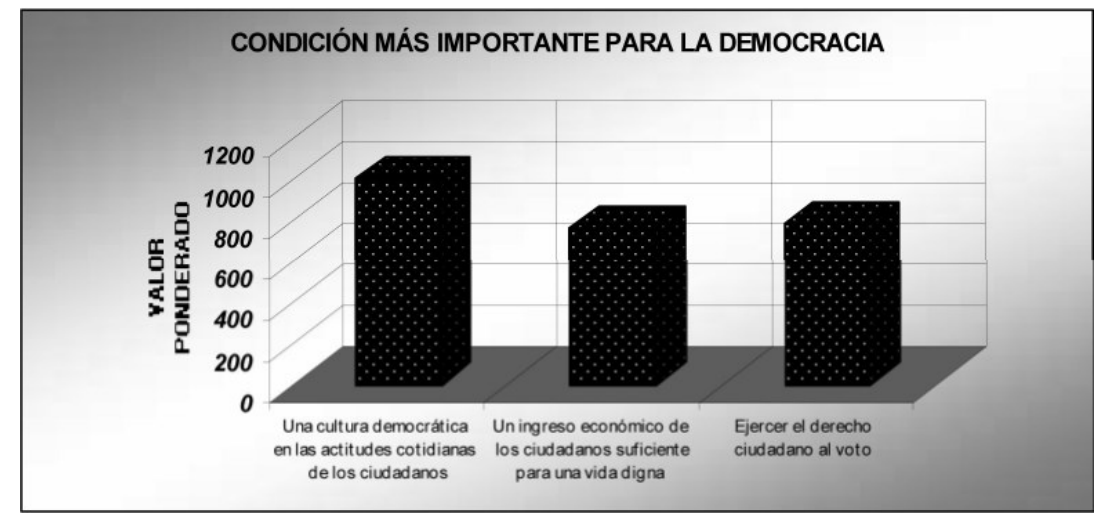

Fuente: Dirección de Posgrado e Investigación de La Salle Pachuca.

\section{Valoración sobre el Estado de Derecho en México}

Uno de los indicadores de la calidad de determinado régimen democrático es el la vigencia del Estado de derecho, y éste tiene una relación íntima con la impartición de justicia, el resultado de la encuesta no deja lugar a dudas:

93.6\% del alumnado encuestado piensa que en México la justicia es parcial

para las personas que tienen algún tipo de poder ya sea económico, político o social. Lo anterior se complementa con la calificación del proceso de acceso a la justicia a los ciudadanos pobres, cuyo resultado fue 2.19 (donde 1: sin desarrollo; 2: bajo desarrollo; 3: medianamente desarrollado; 4: alto desarrollo y 5: completamente desarrollado).

También se inquirió acerca del uso que se le da a la aplicación de las leyes mediante cuatro opciones: buscar la justicia; como pretexto para cometer arbitrariedades; para defender los intereses de la sociedad; y para defender los intereses de la gente con poder. Es decir dos opiniones positivas y dos negativas, de manera que si agrupamos las positivas (buscar la justicia y defender los intereses de la sociedad) sumamos una adscripción de opinión del $41.4 \%$, y si agrupamos las negativas (como pretexto para cometer arbitrariedades y defender los intereses de la gente con poder) sumamos $52.4 \%$. 
En relación a calificar procesos tales como: capacidad del Estado Mexicano para hacer cumplir la ley, se obtuvo una calificación de 2.57 (entre bajo y mediano desarrollo). Este eje analítico cobra importancia por un tema asociado a un deficiente Estado de derecho el cual se refiere a la corrupción. Dicho tema resultó ser la principal preocupación, junto con la pobreza y la inseguridad, con valores relativos de $33.1 \%$, $25 \%$ y $20.2 \%$ respectivamente (en la gráfica 3 se incluye el dato del número de alumnos que optaron por dichos problemas), respecto a la calificación que se le otorgó al proceso combate a la corrupción fue de 1.94 (bajo desarrollo).

Gráfica 3. Principal preocupación del los estudiantes de licenciatura de La Salle Pachuca

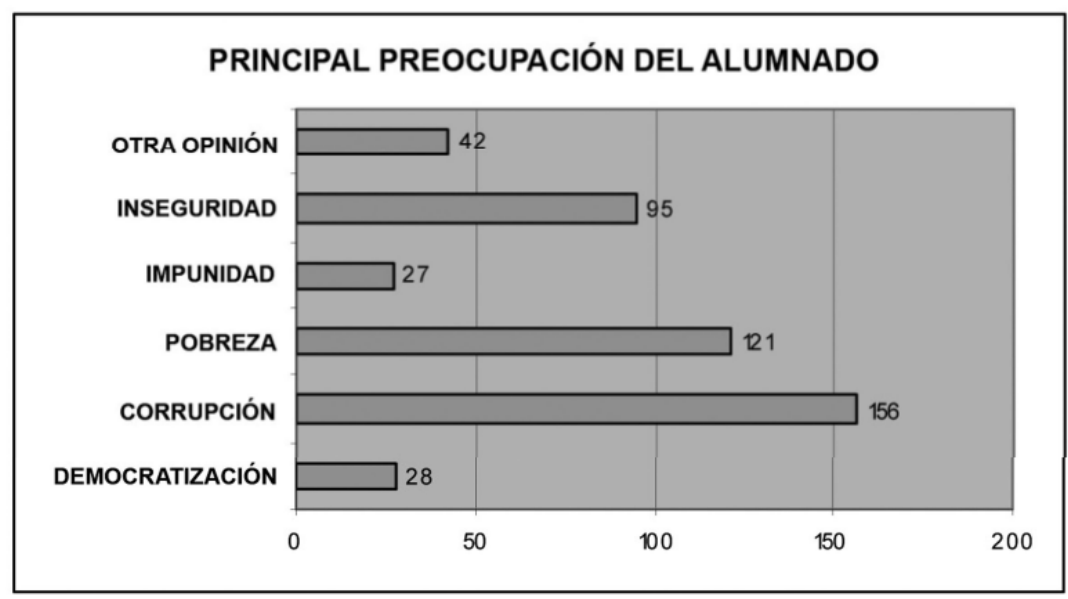

Fuente: Dirección de Posgrado e Investigación de La Salle Pachuca.

\section{Valoración sobre la clase política en México}

Importante factor en la vida política de las naciones que se precian de ser democráticas son los partidos políticos, por lo que se exploró la opinión del alumnado respecto a su existencia en México. Se puede considerar que existe un evidente descrédito de los partidos políticos ya que más de la mitad del alumnado (51.8\%) considera que son fuente de ingreso económico para los políticos afiliados (ver gráfica 4). 
Gráfica 4. Razones de la existencia de los diferentes partidos políticos en

\section{México}

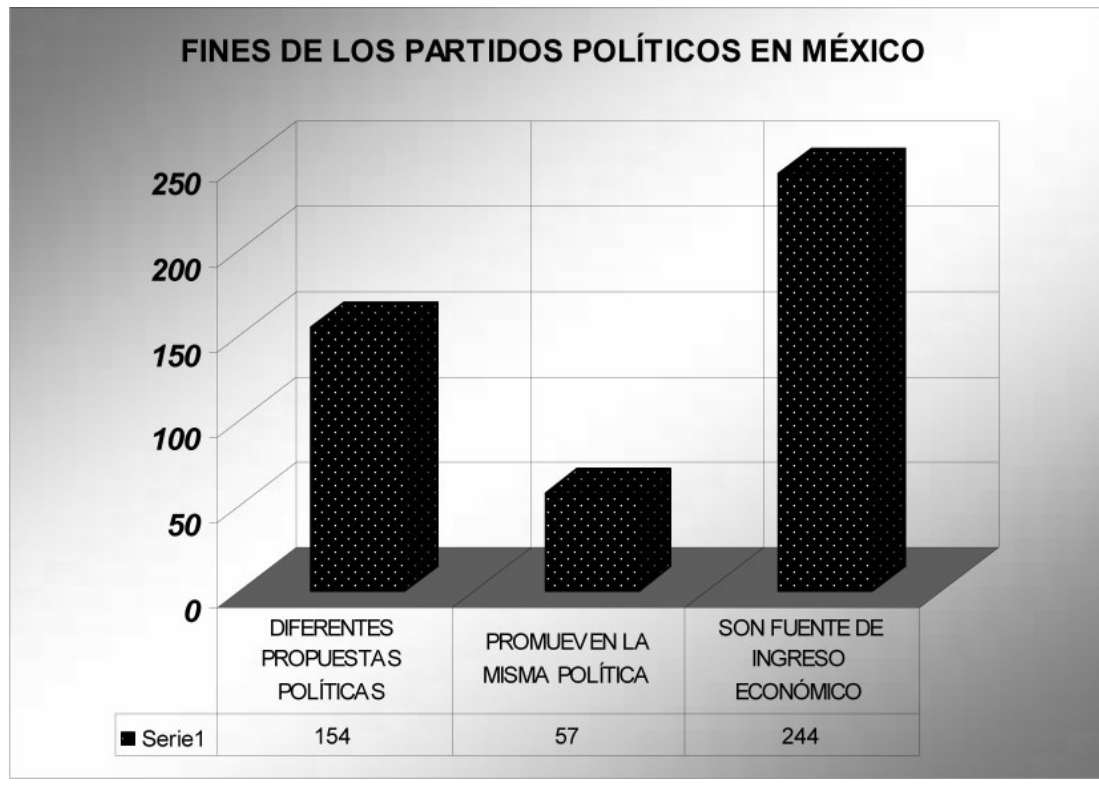

Fuente: Dirección de Posgrado e Investigación de La Salle Pachuca.

Mediante la escala Lickert resultó que existe un "parcial desacuerdo" ante las tres siguientes afirmaciones: En México los logros en política social y económica difundidos por el Gobierno de la República son verdaderos; en México la política contribuye a mejorar el nivel de vida de todos los mexicanos; y en México los partidos políticos son indispensables para que el país mejore.

Posteriormente se da el resultado de los niveles de confianza que se tiene en determinadas instituciones o grupos de personas según una escala del 0 al 5 (donde 0 representa ninguna confianza y 5 la absoluta confianza. Por ahora baste decir que los resultados anteriores se confirman con las siguientes puntuaciones: partidos políticos 1.23; El Gobierno Federal 2.17; el Gobierno Estatal 2.19 y los diputados y senadores 1.53 . 


\section{Noción y autoconcepto de ciudadanía}

El autoconcepto como ciudadano en términos de que la política puede ser ajena a determinado porcentaje del alumnado, o bien que se tiene una participación formal en el sentido de sólo votar en la elección de gobernante, o de la ciudadanía sustantiva en el sentido de interesarse e informarse de la política, además de participar más allá del voto, fue objeto de indagación. El resultado indica que mayoritariamente se tiene un autoconcepto de ciudadanía formal (54.8\%), seguido por una ciudadanía sustantiva $(25.1 \%)$ y por último la percepción de que la política les es ajena al $16.6 \%$ (ver gráfica 5).

\section{Gráfica 5. Autoconcepto de ciudadano respecto a la participación política}

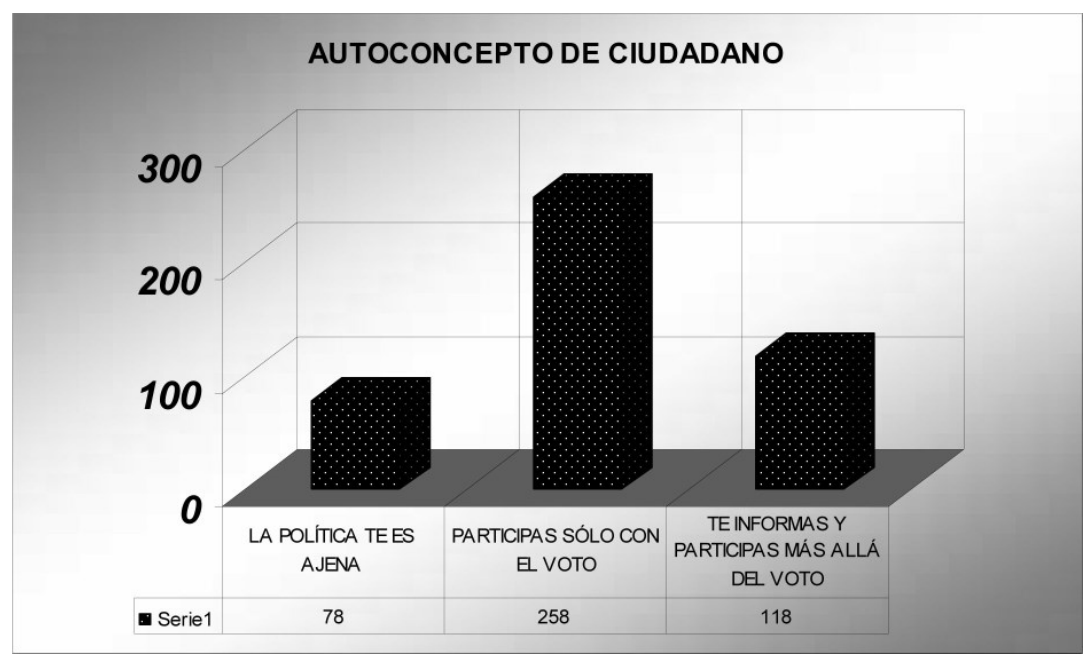

Fuente: Dirección de Posgrado e Investigación de La Salle Pachuca.

En la jerarquización de opciones para obtener valores ponderados se obtuvo que los principales atributos del ciudadano, en orden de importancia son los derechos y obligaciones para los individuos de un país; seguido de pertenecer a una nación y por último participar en la política. Se considera que este resultado refleja una mayor valoración por la noción jurídica y adscriptiva, por sobre una noción participativa, lo cual es coherente con una noción de ciudadanía más formal que sustantiva. 
También se consideró importante indagar acerca de la noción de ciudadanía en tanto ésta puede ser republicana o liberal, así como una opción que incluya estas dos visiones, en este sentido la opción integradora fue la que obtuvo mayor puntuación, aunque por ligero margen, seguida por la noción liberal y por último la republicana (gráfica $6)$.

\section{Gráfica 6. Noción de ciudadanía liberal, republicana o integradora}

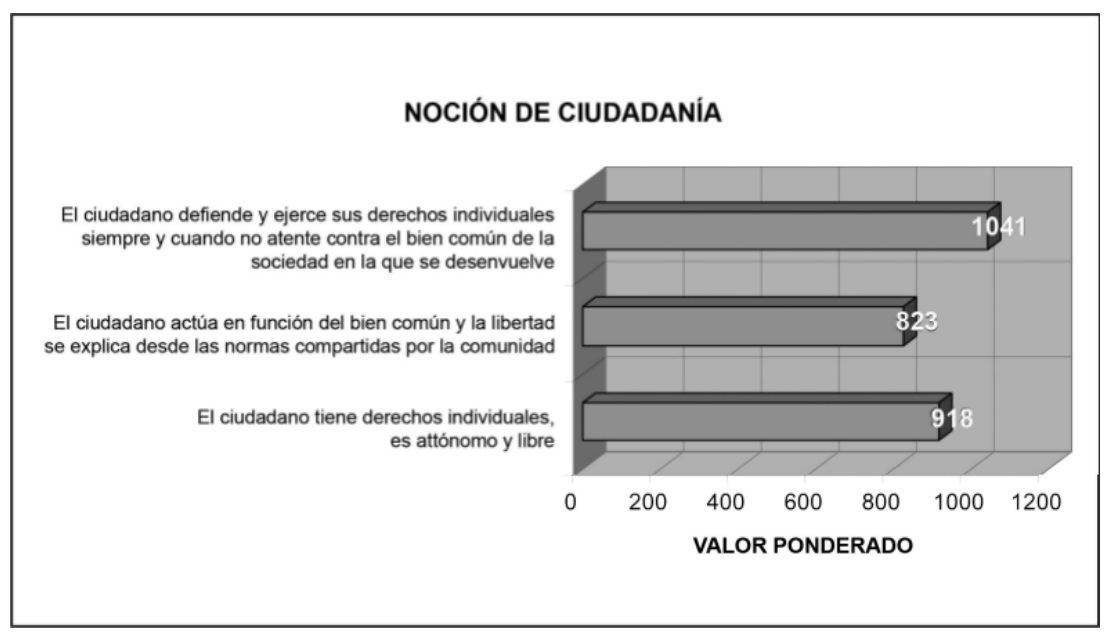

Fuente: Dirección de Posgrado e Investigación de La Salle Pachuca.

\section{Interculturalidad}

También se consideró importante indagar sobre el respeto y tolerancia hacia el otro, pues en tanto la sociedad se complejiza cada vez más, surgen nuevas formas de identidad que repercuten en una mayor diversidad desde el punto de vista social, cultural, sexual, política, etc. Por lo anterior se exploró la

Xihmai 72 
Revista Xihmai IV (08), 55-86, ISSN: 1870_6703, 2009

proclividad hacia el interculturalismo y el resultado fue claro: $84 \%$ del alumnado encuestado piensa que en México es preferible el respeto, el diálogo y la convivencia de personas con diferente cultura para el mejor ejercicio de la ciudadanía ${ }^{10}$. Por otro lado, $86.8 \%$ del alumnado considera que para la convivencia entre los alumnos de La Salle Pachuca es mejor la presencia de cristianos y no cristianos con características sociales y culturales diversas; mientras que sólo $9.1 \%$ piensa que lo mejor sería la presencia sólo de alumnos que compartan la fe cristiana y con características sociales y culturales semejantes (ver gráfica 7).

\section{Gráfica 7. Mejores condiciones de convivencia entre los alumnos de La}

\section{Salle Pachuca}

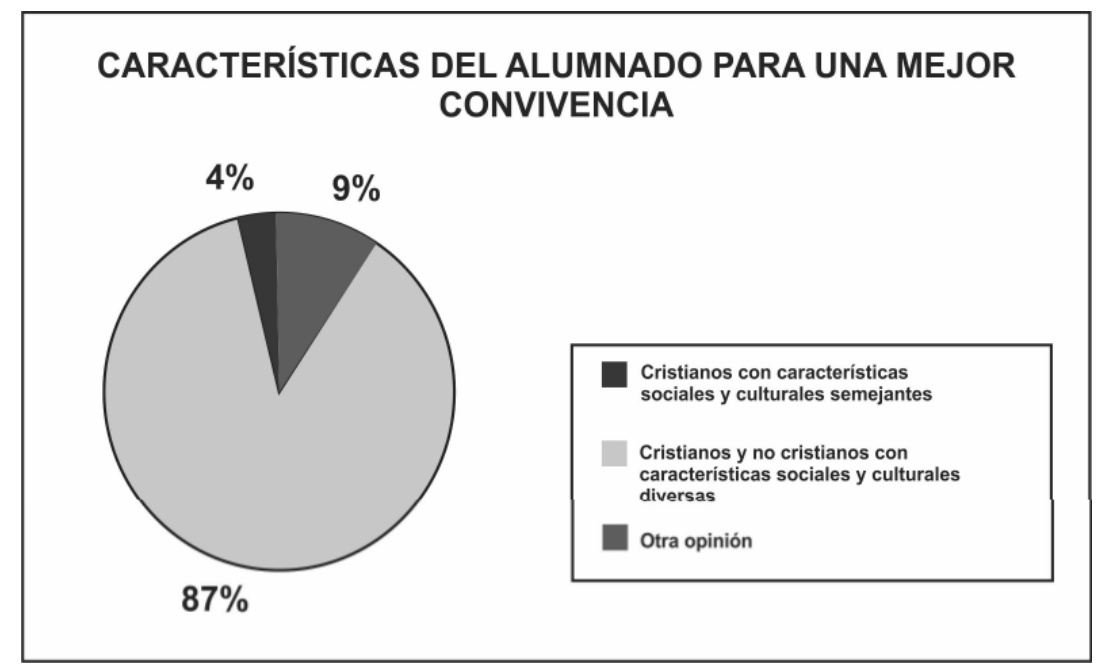

Fuente: Dirección de Posgrado e Investigación de La Salle Pachuca.

Mediante la escala Lickert, se obtuvo un total acuerdo hacia las siguientes afirmaciones: Los homosexuales y las lesbianas son personas que tienen los mismos derechos y obligaciones de los demás y deben ser aceptadas como cualquier otra persona; y en las universidades lasallistas pueden convivir 
Las otras opciones fueron: la asimilación de las diferentes culturas (como las indígenas) hacia una única que determine una identidad nacional (7.2\%), y la tolerancia hacia otras culturas de nuestro país (como las indígenas) pero sin convivencia con ellas (7.6\%).

armónicamente estudiantes con distintos credos religiosos 0 sin credo alguno.

\section{Pobreza}

La opción por los pobres es parte medular del ideario lasallista por lo que mediante la escala lickert se exploró tal aspecto y el resultado indica que existe un parcial acuerdo para las siguientes dos afirmaciones: las universidades lasallistas deben tener un compromiso político que tienda a transformar las estructuras económicas, sociales y culturales que generan pobreza; y el egresado lasallista debe estar comprometido con los pobres, marginados y excluidos, y reflejar este compromiso en su ejercicio profesional.

Asimismo mediante la jerarquización de alternativas para obtener puntuaciones ponderadas, se obtuvo el resultado de que para combatir la pobreza se requiere, en orden de importancia: promover proyectos de desarrollo de las comunidades; llevar a cabo programas de beneficencia y asistencia social; y, por último luchar para que el sistema económico dominante sea reemplazado por otro (Gráfica 8).

\section{Gráfica 8. Combate a la pobreza}

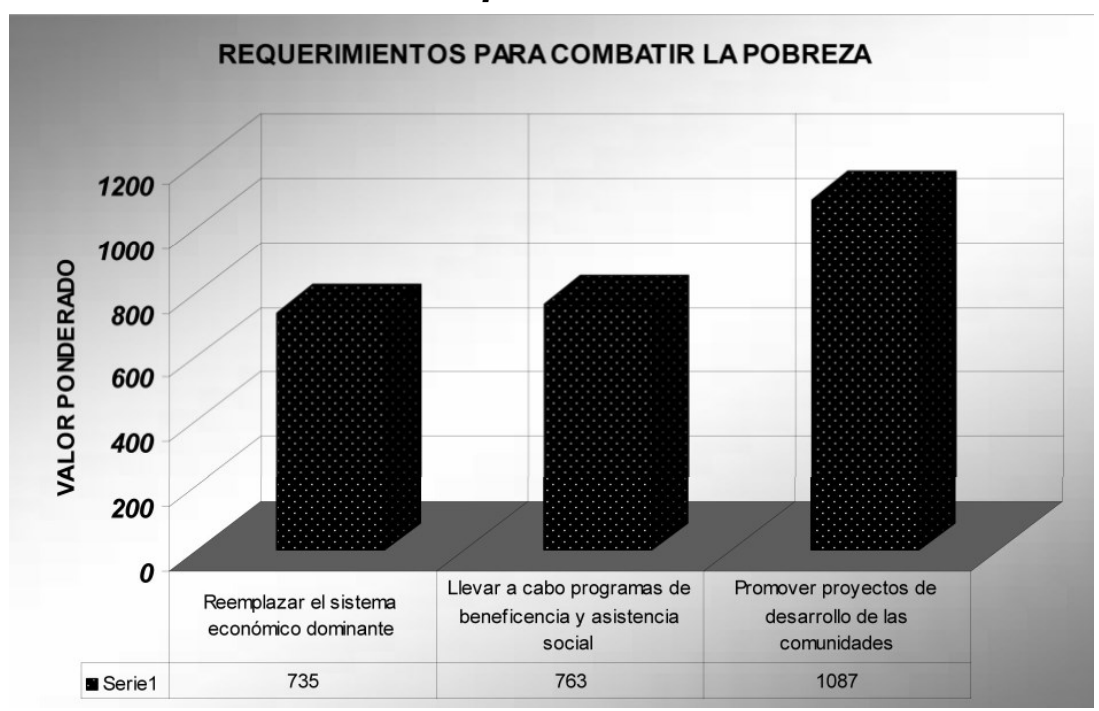

Fuente: Dirección de Posgrado e Investigación de La Salle Pachuca. 


\section{Valoración sobre la Universidad La Salle Pachuca}

Se considero también importante indagar acerca de la opinión del alumnado encuestado sobre lo que consideran debe ser el objetivo de las universidades. La encuesta arroja el siguiente resultado: $63.9 \%$ considera que dicho objetivo es generar, conservar, sistematizar y transmitir el conocimiento; $21.9 \%$ opta por que es el favorecer a los sectores empobrecidos y marginados de la sociedad al poner a su servicio el conocimiento generado; mientras que $9.1 \%$ opta por el favorecer a los sectores dominantes de la sociedad al poner a su servicio el conocimiento generado. En la gráfica 9 se especifica el número de alumnos y la opción elegida.

\section{Gráfica 9. Principal objetivo de las universidades}

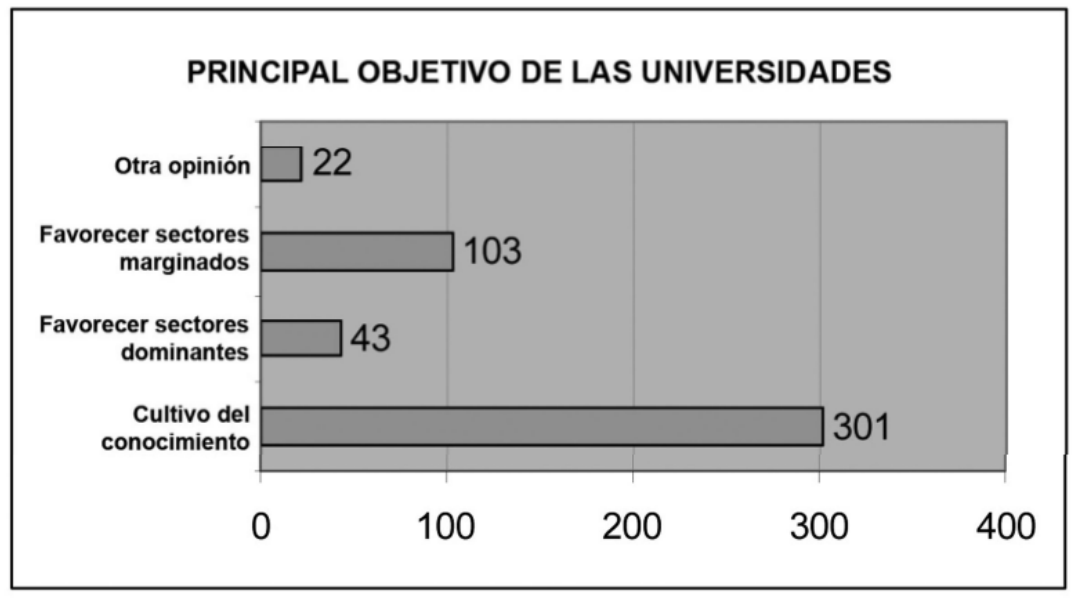

Fuente: Dirección de Posgrado e Investigación de La Salle Pachuca.

Para especificar la opinión acerca de la Universidad La Salle Pachuca se inquirió acerca de su papel social: $51 \%$ del alumnado encuestado opina que principalmente prepara profesionales aptos para luchar a favor de transformaciones sociales que disminuyan las desigualdades sociales y económicas; por otra parte $43,7 \%$ opina que los preparan básicamente para el mercado de trabajo y ser competentes en determinada disciplina (ver gráfica

10).

Gráfica 10. Universidad La Salle Pachuca 


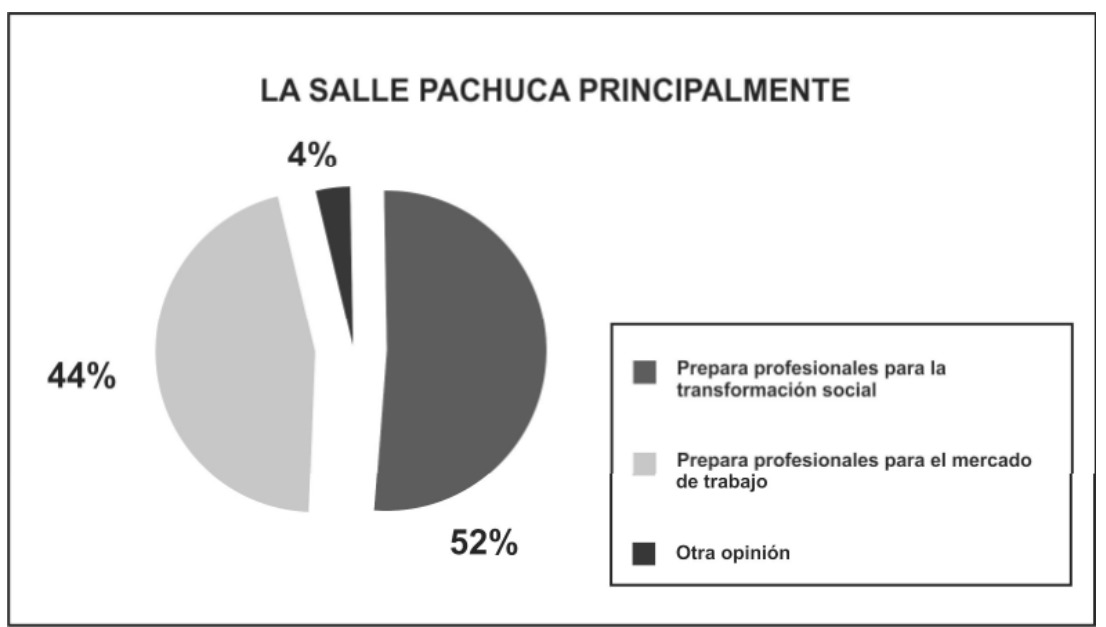

Fuente: Dirección de Posgrado e Investigación de La Salle Pachuca.

Complemento al ítem anterior se cuestionó acerca de la idea que se forman en La Salle sobre el bienestar personal. Mayoritariamente $(77.9 \%)$ opinan que éste se promueve en función del compromiso con la sociedad y la ayuda a los necesitados, mientras que 16.3 $\%$ opinan que se promueve en función de la adquisición de bienes materiales y el deseo de éxito económico.

\section{Formación e información política}

Se consideró importante explorar también el medio de donde considera el alumnado, ha obtenido sus valores éticos y políticos. Más de las tres cuartas partes de los encuestados $(77.7 \%)$ considera haber obtenido los mencionados valores a través de su cultura y experiencias derivadas de la familia y de la localidad donde han vivido (ver gráfica 11); en orden de importancia le sigue la opinión de haberlos adquirido mediante su formación universitaria $(10.8 \%)$ y su participación en alguna organización social o política $(4.2 \%)$ y es muy bajo la influencia de la religión profesada (1.9\%).

\section{Gráfica 11. Universidad La Salle Pachuca}




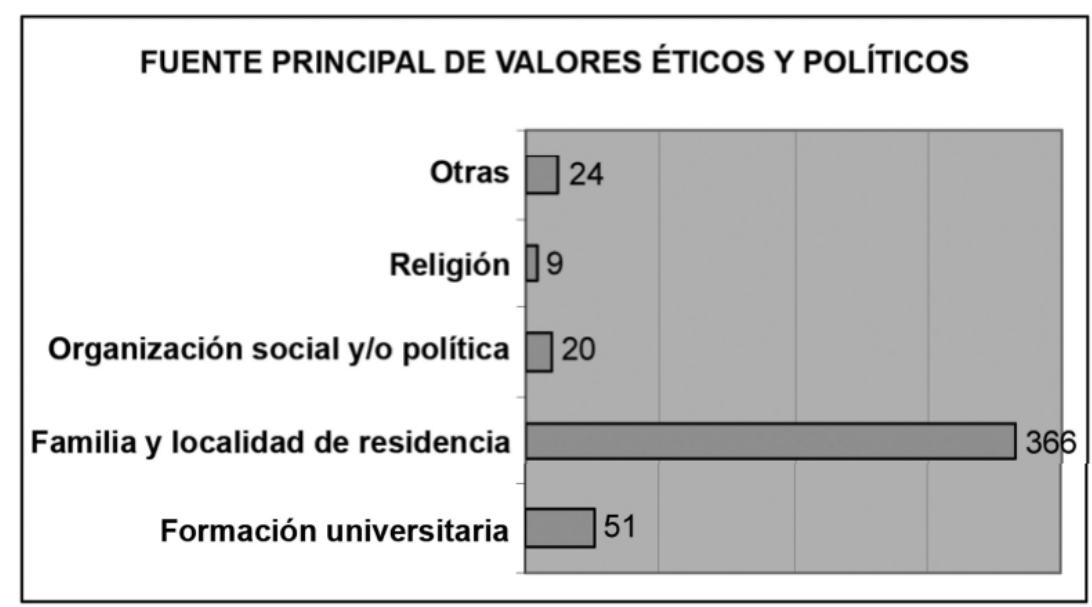

Fuente: Dirección de Posgrado e Investigación de La Salle Pachuca.

Se indagó acerca del principal medio de información de los estudiantes por medio de una jerarquización para obtener valores ponderados (ver gráfica

12). En orden descendiente los resultados fueron los siguientes: televisión; periódicos y revistas; Internet; conversando con familiares; radio; platicando con amigos y compañeros de escuela; escuchar y platicar con profesores.

\section{Gráfica 12. Fuentes de información política}




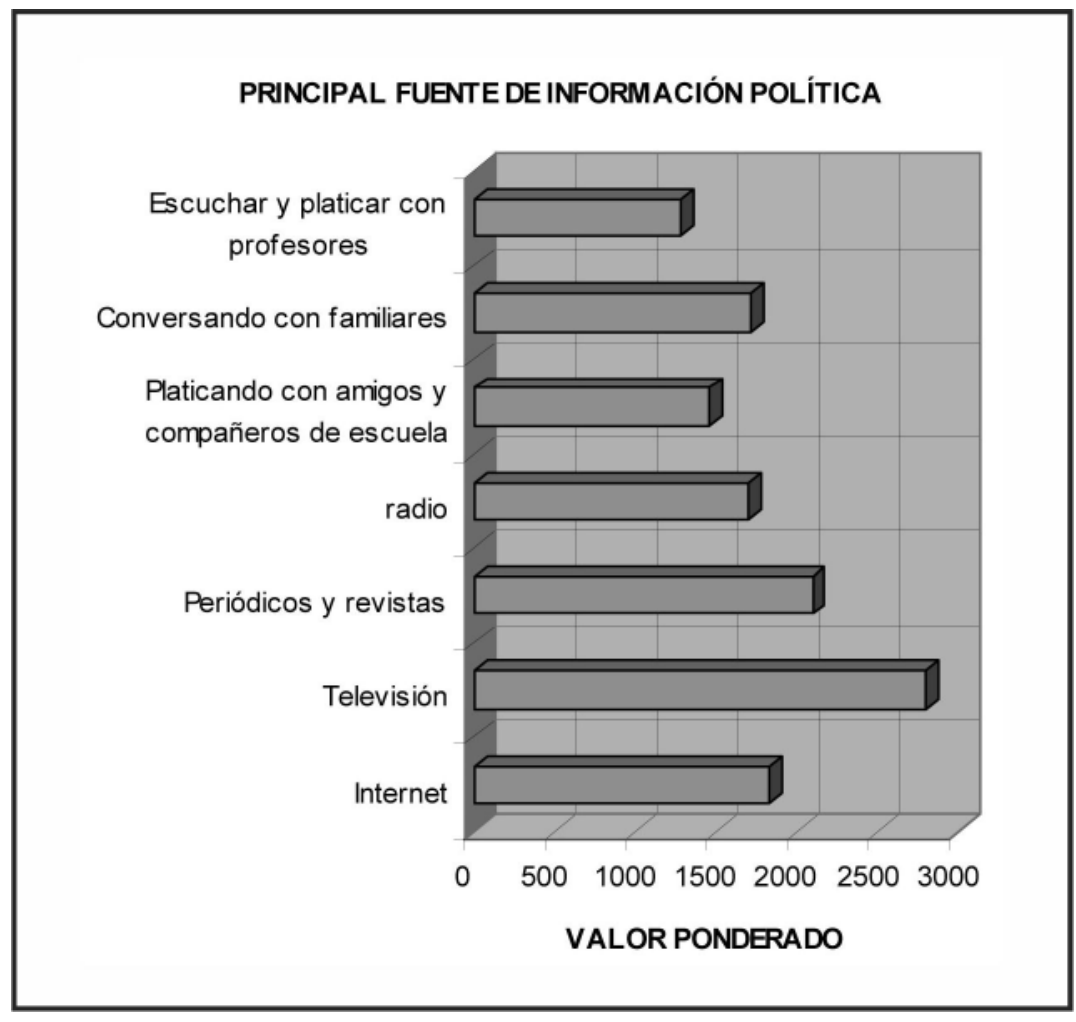

Fuente: Dirección de Posgrado e Investigación de La Salle Pachuca.

\section{Confianza en instituciones}

En una del instrumento se planteó determinar el nivel de confianza de instituciones y grupos de personas, según una escala del 0 al 5 , donde 0 representa ninguna confianza y 5 la absoluta confianza, así los promedios obtenidos se indican en el cuadro 1. Se confirma que la familia es la institución más confiable (resultado que se confirma en otras encuestas) seguida por los profesores de La Salle Pachuca; el ejército; la Comisión Nacional de Derechos Humanos y los directivos de La Salle Pachuca, por mencionar a quienes obtuvieron más de tres puntos (tres puntos corresponderían a la mitad de la escala). Cabe mencionar entonces que tanto profesores como directivos de la institución tienen un rango aceptable de confianza para el alumnado encuestado.

Por otro lado, se confirma la mala reputación de los partidos políticos (1.23), los diputados y senadores (1.53), y la policía estatal y municipal (1.95). Llama la atención también el bajo índice de confianza en los dirigentes estudiantiles de La Salle Pachuca (2.07) y de la iglesia (2.41)

Cuadro 1. Estadísticos descriptivos de los niveles de confianza a instituciones 


\begin{tabular}{|c|c|c|c|c|c|}
\hline & $\mathrm{N}$ & Mínimo & Máximo & Media & Desv. típ. \\
\hline La Familia & 464 & 0 & 5 & 4,78 & ,629 \\
\hline $\begin{array}{l}\text { Los profesores de la Salle } \\
\text { Pachuca }\end{array}$ & 462 & 0 & 5 & 3,45 & 1,108 \\
\hline El ejército & 460 & 0 & 5 & 3,14 & 1,446 \\
\hline $\begin{array}{l}\text { La Comisión Nacional de } \\
\text { Derechos Humanos }\end{array}$ & 461 & 0 & 5 & 3,12 & 1,232 \\
\hline $\begin{array}{l}\text { Los directivos de La Salle } \\
\text { Pachuca }\end{array}$ & 458 & 0 & 5 & 3,10 & 1,349 \\
\hline Los empresarios & 461 & 0 & 5 & 2,73 & 1,315 \\
\hline $\begin{array}{l}\text { Los medios de } \\
\text { comunicación }\end{array}$ & 462 & 0 & 5 & 2,70 & 1,165 \\
\hline $\begin{array}{l}\text { Las organizaciones de } \\
\text { ciudadanos }\end{array}$ & 460 & 0 & 5 & 2,70 & 1,258 \\
\hline AFI y $P G R$ & 457 & 0 & 5 & 2,67 & 1,435 \\
\hline $\begin{array}{l}\text { El Instituto Federal } \\
\text { Electoral }\end{array}$ & 460 & 0 & 5 & 2,62 & 1,383 \\
\hline $\begin{array}{l}\text { El Presidente de la } \\
\text { República }\end{array}$ & 463 & 0 & 5 & 2,47 & 1,359 \\
\hline La Iglesia & 460 & 0 & 5 & 2,41 & 1,577 \\
\hline El Gobierno Estatal & 459 & 0 & 5 & 2,19 & 1,353 \\
\hline El Gobierno Federal & 462 & 0 & 5 & 2,17 & 1,317 \\
\hline Los servidores públicos & 460 & 0 & 5 & 2,14 & 1,252 \\
\hline El poder judicial & 460 & 0 & 5 & 2,11 & 1,320 \\
\hline $\begin{array}{l}\text { Los dirigentes } \\
\text { estudiantiles de La Salle } \\
\text { Pachuca }\end{array}$ & 458 & 0 & 5 & 2,07 & 1,555 \\
\hline $\begin{array}{l}\text { La policía municipal y } \\
\text { estatal }\end{array}$ & 460 & 0 & 5 & 1,95 & 1,300 \\
\hline $\begin{array}{l}\text { Los diputados y } \\
\text { senadores }\end{array}$ & 460 & 0 & 4 & 1,53 & 1,191 \\
\hline $\begin{array}{l}\text { Los partidos políticos } \\
\mathrm{N} \text { válido (según lista) }\end{array}$ & $\begin{array}{l}461 \\
452\end{array}$ & 0 & 5 & 1,23 & 1,246 \\
\hline
\end{tabular}

Fuente: Dirección de Posgrado e Investigación de La Salle Pachuca.

En otra parte del cuestionario se indagó acerca de lo que el alumnado encuestado opina sobre el grado de desarrollo de algunos procesos de índole sociopolítico (cuadro 2). 


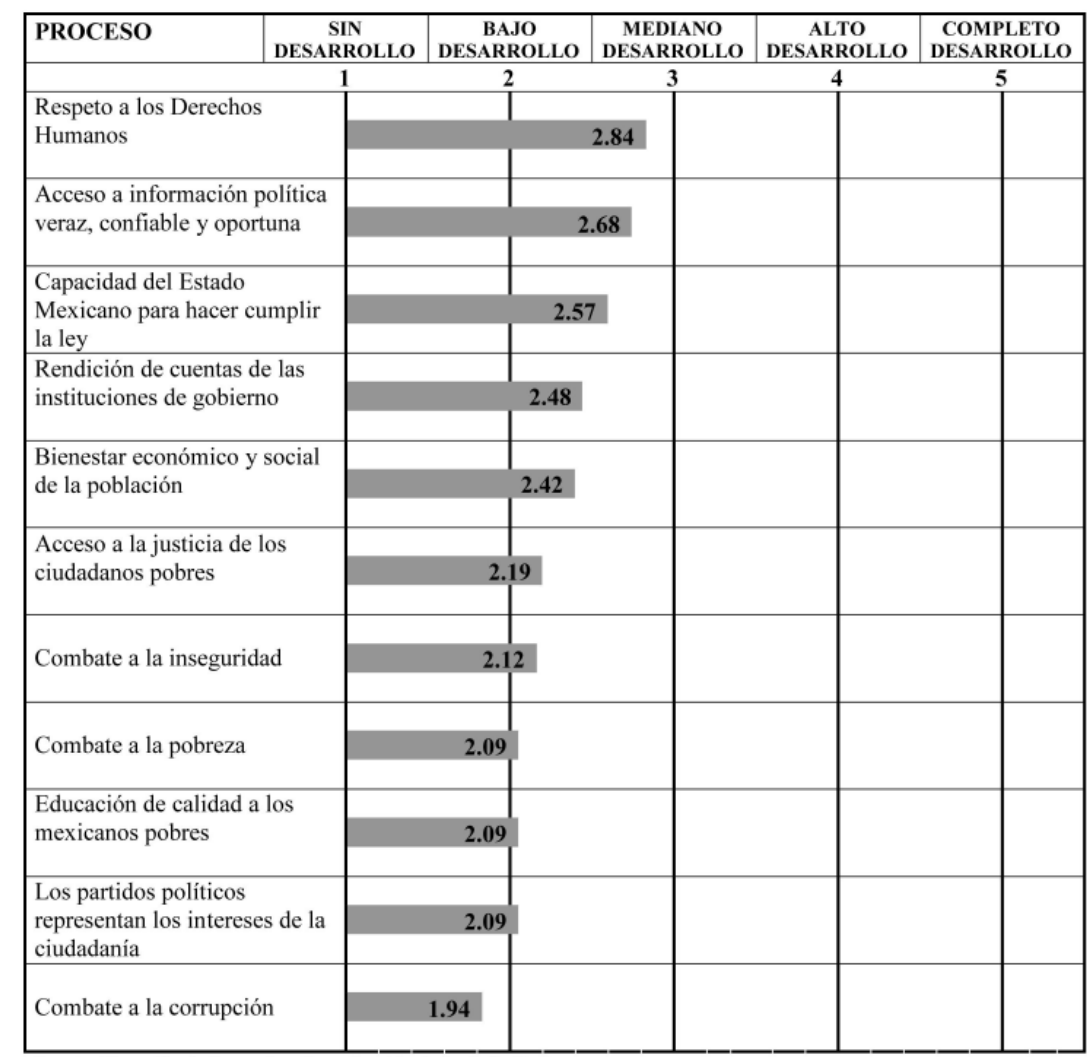

Fuente: Dirección de Posgrado e Investigación de La Salle Pachuca.

\section{Discusión}

La mayoría (52\%) del alumnado encuestado de licenciatura de la Universidad La Salle Pachuca considera que la democracia en México o bien es igual que antes o nunca ha existido (Se considera que la referencia básica del posible antes y después serían las elecciones federales de 2000 donde hubo una alternancia del partido político en poder del Ejecutivo). Lo cual no se considera una valoración positiva para la democracia en México y representa una opinión que comparten la mayoría de ciudadanos según las encuestas reportadas. Esta opinión puede estar matizada por el relativamente reciente proceso electoral de 2006 que fue muy competido y se desarrolló en gran medida mediante propaganda negativa (ataques al contrincante). Dicho proceso fue denunciado como plagado de irregularidades electorales, o de haber sido francamente fraudulento.

Lo anterior tiene relación con que más de la mitad del estudiantado $(54.1 \%)$ esta poco satisfecho con la democracia mexicana. En suma existe una deficiente valoración de la calidad de la democracia en México, lo cual también se refleja en que los encuestados están parcialmente en desacuerdo respecto a que los ciudadanos mexicanos influyen en las decisiones del gobierno. Hay que tomar en cuenta, sin embargo, que $44 \%$ piensa que sí ha mejorado la democracia en México, quizá por el hecho de haber terminado la hegemonía priísta en el poder ejecutivo.

Lo anterior no implica que el alumnado no tenga un claro espíritu democrático en el que prevalece una posición principalmente culturalista e institucional como vías para 
mejorar nuestra democracia. La posición culturalista se refleja en que se piensa que la condición más importante para la democracia es una cultura democrática en las actitudes cotidianas de los ciudadanos; y la institucional en que la opinión dominante es recurrir a las vías legales aunque éstas no sean las idóneas para favorecer la democracia.

Se considera que el alumnado encuestado tiene claridad sobre uno de los problemas torales de México: el deficiente Estado de derecho prevaleciente, ya que una amplia mayoría considera que la justicia es parcial con personas con algún tipo de poder. Por otro lado ligeramente más de la mitad del estudiantado tiene una percepción negativa respecto a la aplicación de la justicia en México y considera que la capacidad del Estado Mexicano para cumplir la ley estaría entre un bajo y un mediano desarrollo y su principal preocupación es la corrupción. Lo anterior da cuenta de una juventud desencantada con la aplicación de la justicia en México, en buena medida porque dicha aplicación está en relación con la condición política y socioeconómica de las personas.

Al igual que en la mención anterior, la percepción de los estudiantes de licenciatura de La Salle Pachuca acerca de la clase política mexicana es lamentable pues se infiere que lo más importante para ellos el beneficio personal. Asimismo no hay crédito para los logros que difunde el Gobierno de la República y, en suma, la política no mejora las condiciones de vida de los mexicanos. Sería necesario una investigación más a fondo para determinar las causas, aunque es muy probable (al menos para quien esto escribe) que los años de demagogia priísta y las visiones optimistas de los gobiernos de Vicente Fox y Felipe Calderón que contrastan con la realidad sentida de la población, tengan mucho que ver en esta percepción, bajo influencia tanto de opinión de padres y familiares mayores, como de opinión propia.

Se considera que la mala valoración que se tiene sobre la clase política en México, la calidad de la democracia y del Estado de derecho, se traducen en una noción de ciudadanía más formal (por ejemplo la participación con el voto electoral y el concepto de ciudadanía más apegado a lo jurídico y adscriptivo) que sustantiva (la participación en la política más allá del voto, en diferentes ámbitos de la vida política, económica y social), por otro lado se tiene mayoritariamente (aunque no por mucho rango) una noción integradora tomando como referencia el debate entre el republicanismo (el bienestar común por encima de los derechos individuales) y el liberalismo (los derechos individuales por encima del bien común), lo cual sugiere que se tiene una idea incluyente sobre estos tópicos que históricamente han estado en debate. Se considera también que el mencionado alumnado tiene una franca proclividad hacia el interculturalismo. Es decir de respeto hacia el otro, que se distingue ya sea por su condición social, cultural, religiosa o de preferencia sexual.

Como ya se mencionó, existe adhesión (de parcial acuerdo) hacia el compromiso con los pobres y del combate a la pobreza por parte de la Universidad La Salle Pachuca. Por otro lado, respecto a la forma de combatir la pobreza, la opción asistencialista y la radical (reemplazo del sistema económico vigente) tienen una adscripción semejante y la forma intermedia (desarrollo de proyectos) obtiene la mayor puntuación, es decir, se tiene mayoritariamente un punto de vista moderado respecto a la mejor forma de combatir la pobreza. Cabe recordar que ésta es la segunda preocupación (después de la corrupción) del alumnado de La Salle Pachuca. 
El conocimiento es el objetivo más importante de las universidades en opinión de la mayoría de los estudiantes de licenciatura y para la mitad de ellos La Salle Pachuca, a través de la preparación de profesionales, lucha para disminuir las desigualdades sociales de México, aunque casi $44 \%$ piensa que sólo prepara para el mercado de trabajo, es decir están divididas las opiniones pero prevalece la valoración de la función social de la institución, opinión que se ve confirmada al responder más de las tres cuartas partes del alumnado que su bienestar personal esta en función del compromiso social con los más necesitados. Es decir, sin que haya un acuerdo marcadamente dominante, se considera que en general ha permeado en la opinión del estudiantado (al menos en lo declarativo) el compromiso lasallista para con los desfavorecidos por esta sociedad.

La televisión es el principal medio de información política para más de la mitad del alumnado (al menos para el $58 \%$ de los estudiantes encuestados). Aunque no se puede saber en específico cuáles son los programas o noticiarios más vistos, se sabe que el duopolio televisivo en México, en general, tiene muy parecidos recursos y sesgos para ofrecer "información" dirigida a formar opinión. También es conocido que la información masiva más confiable se encuentra en la prensa escrita que, junto con Internet, son las fuentes que siguen en importancia. También se confirma que la familia y la localidad de residencia son las principales fuentes de formación de valores, y que en este aspecto no es tan relevante la formación universitaria, cuestión que se considera digna de reflexión, en tanto que importantes referentes lasallistas sobre la educación política, llaman la atención sobre la importancia de la formación ciudadana.

Se concluye que la dimensión política en la educación superior debe hacerse explícita e implícita en la formación de los profesionales. a fin de generar también procesos de formación de una ciudadanía realmente informada crítica y reflexiva que ejerza un efecto multiplicador en los campos de influencia y convivencia de los profesionales lasallistas (y de todos los profesionales egresados de cualquier Institución de Educación Superior) a fin de coadyuvar a la construcción de la democracia, que aún no a su consolidación como algunos piensan. Se considera que este proceso está también estrechamente ligado a la resignificación de la relación de las universidades con la sociedad, discusión que habría que generar en otro espacio. 


\section{Fuentes de Consulta}

- ACOSTA Silva, Adrián (2005), Pluralismo y democracia, en: "nexos", año 27, vol. XXVII, num. 325, enero de 2005

AGUAYO, Enrique (2006), Misión contemporánea de la Universidad La Salle: ser lugar de convivencia de los hombres, en: Franz, Craig (Editor) "Reflexiones sobre la educación superior lasallista", EstadosUnidos de América:

Asociación Internacional de Universidades Lasallistas

- $\quad$ ALMOND, A. Gabriel y Sydney Verba (1992) La cultura política, en: "Diez textos básicos de ciencia política", Espana: Ariel, p 171-201

- AZMITIA, Oscar (2006), Proyecto educativo regional Lasallista latinoamericano-PERLA, en: Cuadernos MEL 31, Hermanos de las Escuelas Cristianas, Roma, Italia

- GARCÍA Cabrero, Benilde (2002), Educación, ciudadanía y participación democrática, en: "Deconstruyendo la ciudadanía. Avances y retos en el desarrollo de la cultura democrática en México", México: SEGOB, SEP, IFE.

CERVANTES, José (2006), El futuro de la universidad cat ólica ante la postmodernidad, en: Franz, Craig (Editor) "Reflexiones sobre la educación superior lasallista", Estados Unidos de América: Asociación Internacional de Universidades Lasallistas

- DE T HOMASIS, Louis (2006), La educación superior lasallista. Una búsqueda llena de matices de realidad paradójicos y ambiguos, en: Franz, Craig (Editor) "Reflexiones sobre la educación superior lasallista", Estados Unidos de América: Asociación Internacional de Universidades Lasallistas

- DURAND Ponte, V. Manuel (1998), La cultura política de los alumnos de la UNAM, México: UNAM, Porrúa.

FLORES Dávila, Julia y Yolanda Meyenberg (2000), Ciudadanos y Cultura de la Democracia. Reglas, Instituciones y valores de la democracia. México; IFE

- $\quad$ FRANZ, Craig (2006), Fieles a una visión, inquebrantables por un sueño, en: Franz, Craig (Editor) "Reflexiones sobre la educación superior lasallista", Estados Unidos de América: Asociación Internacional de Universidades Lasallistas

HEC, Hermanos de las Escuelas Cristianas (2007), Circular 455, Documentos del $44^{\circ}$ Capítulo General "Ser Hermanos hoy: ojos abiertos corazones encendidos", Roma, Italia

- $\quad$ HENGEMÜLE, Edgard (2006), La universidad lasaliana, en: Franz, Craig (Editor) "Reflexiones sobre la educación superior lasallista", Estados Unidos de América: Asociación Internacional de Universidades Lasallistas

- MEJÍA, Humberto (2005), Noción de ciudadanía en universitarios de ciencias sociales y humanidades: una generación de la UAEH en 2005. Tesis de maestría. Universidad Autónoma del Estado de 
Hidalgo. México

MOLINA, Amelia (2004), Indicadores y procesos en la conformación de la cultura política de los jóvenes del estado de Hidalgo: el caso de los instructores comunitarios del Consejo Nacional de Fomento Educativo (CONAFE), en: Fabré, Danú; Amelia Molina y Carlos Rodríguez (coord), "Investigación y desarrollo regional en ciencias sociales y humanidades. Hidalgo, Puebla y Tlaxcala, México: UAEH, Praxis.

- LATINOBARÓMETRO (2005), Informe Latinobarómetro 2005, Chile: Corporación Latinobarómetro

- OJEDA, Juan Antonio (2006), Transformación e innovación en las universidades La Salle, en: Franz, Craig (Editor) "Reflexiones sobre la educación superior lasallista", Estados Unidos de América: Asociación Internacional de Universidades Lasallistas

- SEGOB, IFE. Secretaría de Gobernación e Instituto Federal Electoral (2001), Encuesta Nacional Sobre Cultura Política y Prácticas Ciudadanas (ENCUP 2001), México: SEGOB

- SEGOB. Secretaría de Gobernación (2005), Conociendo a los Ciudadanos Mexicanos. Principales Resultados, Tercera Encuesta Nacional sobre Cultura Política y Prácticas Ciudadanas México: SEGOB 